\title{
Professional Partnerships: Supporting the Prepa- ration of Pre-Service Teachers through a Tiered Online Mentoring System
}

\author{
http://dx.doi.org/ijac.v4i3.1718 \\ Barbara Schwartz-Bechet \\ University of Maryland, Adelphi, MD, USA
}

\begin{abstract}
The University of Maryland University College's (UMUC) Department of Education developed a program to increase achievement of secondary school students and increase retention of Master of Arts in Teaching Program (MAT) pre-service teacher candidates entitled, "Professional Partnerships". "Professional Partnerships" is a tiered system of support that promotes stakeholder success by providing online mentoring to pre-service teacher candidates from master mentor teachers. The master mentor teachers were provided with web conferencing workshops and online mentoring in the use of technology tools, The goals of the program are based upon the Redesign of Teacher Education and a research based framework that strengthens partnerships with local school districts to include: improvement of secondary student achievement, enhancement of instruction provided by teacher candidates and in-class teachers through the use of science, technology, engineering, and math (STEM) content as a tool for instruction, improvement, assessment, and communication within the global educational community.
\end{abstract}

Index Terms-online tiered mentoring, STEM, teacher candidate success, student achievement.

\section{INTRODUCTION}

UMUC, a global university and a leader in virtual education and lifelong learning, began the revitalized Master of Arts in Teaching program in the Fall 2009. As a new and innovative program designed to provide career changers with a path towards secondary education certification in nine fields, six of which are in science, technology, engineering, and math (STEM) areas, the transmission of knowledge delivered through the use of unique, state of the art technology tools to develop teacher competencies. The UMUC MAT program has been designed to develop teacher candidates, to foster their strong academic backgrounds, provide experiences with standards based reforms and knowledge of and experience with diverse populations, integrate technology into teaching, understand the need for and types of assessment used to program effectively, through a strong linkage with the K-12 community.

In alignment with the goals of the Redesign of Teacher Education and the Teacher Professional Development Evaluation Guidelines (Haslam, 2010), UMUC faculty and staff, teacher candidates and master mentor teachers collaborate to increase the achievement of students in local public secondary schools. In order to do so, all participants must believe that all students can achieve and at high levels. The development of beliefs regarding student achievement is as important as developing knowledge of pedagogy and classroom management (Pohan, Ward, Kouzekanani, \& Boatright, 2009). Along with the belief comes the directive that students are not only taught but that students will learn (DuFour, 2005). As it has become more feasible over the years to use email and learning platforms to support electronic mentoring (Riel \& Harasim, 1994), one way to accomplish these important goals, is to use an online tiered system of mentoring. The system of mentoring was implemented to facilitate a jointly developed shared mission, vision, and values between the institution of higher education and local school system(s). The project brings stakeholders together and provides equality of experiences and support through the tiered mentoring system. The goals of the project include:

- Use of effective teaching and learning strategies paired with new technologies to result in increased student achievement

- Increase knowledge and use of technology tools by teacher candidates and master mentor teachers for instruction and programming (assessment)

- Integrate STEM methodologies in non-STEM secondary content teaching

- Increase awareness of school needs among teacher candidates and UMUC faculty and staff

- Facilitate the identification of teacher candidates' and master mentor teachers' professional goals (possible increase in reflection and leadership)

- Facilitate professional development of all participants

- Demonstrate use of STEM across content through the use of technology facilitation tools for teaching and learning of all students

- Promote continuing interaction between academia and secondary education public schools

- Increase retention of MAT pre-service teacher candidates

\section{METHODS}

\section{A. Participants}

All teacher candidates in the UMUC MAT program are required to conduct onsite field experiences paired with each online course prior to their student teaching internship; they have little direct sustained contact with secondary education teachers in their content area other than indirect observation and interviewing during their field experiences. Therefore, there is a need for support to our newly accepted teacher candidates in their initial courses. 
Teacher candidates in their first or second course of the MAT program were, and continue to be, invited to apply online through our webpage, http://umuc.edu/matmentor/. A component of the application was for the teacher candidate to identify a long term goal and action plan that would be used to guide the online mentoring sessions. Master mentor teachers, teachers currently teaching in their content area, were recruited through use of Linkedin, Facebook, word of mouth, and directly emailing principals and county administrators. The project aligned each teacher candidate with a master mentor teacher to mentor them during their first, second, or third course in one case. Each course is six credits, 12 weeks per semester, and the mentoring takes place over a minimum of a two semester period, which began January/February 2011 during the Spring semester. The mentoring process utilized technology facilitation and simultaneous renewal.

\section{B. Training}

Each accepted master mentor teacher, an expert in one of the nine content areas that students in the MAT program will become certified in, received an initial mentoring tutorial and then received mentoring from UMUC computer science and content area faculty and staff. The purpose was to enable the master mentor teachers to develop their own use of technology tools and integration of STEM subjects into their teaching of secondary school students to assist their students in achieving greater academic achievement. The master mentor teacher was required to use the new skills with their secondary students and is required to share their outcomes with their mentee, the teacher candidate, and the other mentors in the program. The UMUC faculty and staff provided mentoring support through email, webtycho, Wimba, Skype, and/or other similarly planned online meeting platforms, and individual onsite training at the secondary schools, as needed. Local conference attendance and applications to present at local conferences were required of mentors and mentees during the project. A mentor assistant acts as the liaison between the mentor and the mentee. The mentor assistant is a teacher assistant in the MAT program.

The secondary school master mentor teachers, mentor assistants, and mentees were required to have completed applications and be accepted to participate in the program. Specific requirements were applied. The Principal Investigator (PI) reviewed all applications with the assistance of the mentor assistant.

Master mentor teachers participated in a preliminary training session, which was conducted through a synchronous/asynchronous web enhanced media tool. Master mentor teacher training included ways to use professional teaching standards (Maryland State Department of Education, Redesign of Teacher Education, Common Core) to respond to teacher candidate pedagogical questions and inquiry, understanding needs of adult learners, building trust and communication, data as a way to inform practice, integrating STEM into all content, and working with an understanding of diversity of students and staff. At the time of the synchronous session, the mentor assistant was identified to the master mentor teachers. $100 \%$ participation was documented.

Teacher candidate mentees also took part in a one day training/expectations session. Their training included the creation of a plan that guides their mentoring. They too received their training via a synchronous/asynchronous web enhanced media tool. $100 \%$ participation was documented for mentee viewing of training video.

The mentor assistant received one day of training. The mentor assistant continues to work with five mentors and their mentees. She was instructed on how to provide information to both the mentor and the mentee. The support provided to the master mentor teacher by the mentor assistant included how to assist with questions related to materials, questions about the webtycho platform, and to serve as a point of contact between the mentor and mentee to bridge any communication gaps. The support provided to the mentee included an explanation of the logistics of the mentoring program, feedback that is related to the UMUC learning platform and course specific issues, and preparation for constructive conversations with their mentor.

\section{Mentoring Requirement}

Mentoring for the teacher candidate mentees was required to occur a minimum of two times per month online, by phone, or face to face. Each teacher candidate mentee created a plan that included a teaching goal, which guided what they sought to learn about from the master mentor teacher. The plan was shared with the master mentor teacher. The master mentor teacher then worked with the teacher candidate to facilitate the plan to achieve their teaching related goal.

Mentoring for the master mentor teacher is required to occur two times a semester. Training was and continues to be provided by the computer science/ arts and sciences, and education faculty and staff from UMUC. Technology tools, integrated technology use, and cross content integration of STEM continues to be presented through a series of videos in the webtycho mentor classroom. A technology needs assessment will be provided to the master mentor teachers at the end of the Spring 2011 semester to be documented, analyzed and used for future mentoring purposes.

The PI and specific UMUC faculty and staff took part in two secondary school meetings in order to better understand the dynamics of the school setting that will inform the instruction of the teacher candidates in their pedagogy courses at UMUC, incorporating information on best practice in understanding and working with the school culture.

Continuous review of the alignment of goals has been and will continue to be conducted through the development of a steering committee/leadership team that will bring forth common concerns and chart the course of the project. The leadership team continually monitors the project to ensure that project activities are integrated into the educational reforms of the school and county. The team is comprised of County professional development administrator(s), local school administrator(s), UMUC faculty and staff, a master teacher and a teacher candidate

\section{Assessments}

A. A participant needs assessment survey was distributed online prior to the start of the project, once the participants were selected from the application process. A second survey will be distributed midway, in May 2011, to determine if any changes need to be made to the methods of mentoring, communication, or other programming variables. A summative evaluation survey will be distributed at the end of the project.

B. A meeting log is kept by all participants to document the date, time, and topic discussed and will be col- 
lected at the end of the project. Any more specific descriptions kept by participants will be their own personal property.

C. Master mentor teachers are required to keep a record of the number of times that they used technology tools/software, based on instruction provided by the UMUC faculty, with their students. Master mentor teachers record the opportunities presented and the outcomes achieved by their students after their use. A record is kept in a narrative form and by charting quantitative changes through the recording of grades or number of successful uses of the technology by students. Documentation indicates whether or not support from UMUC faculty and staff improved the quality of the students' academic achievement.

D. Teacher candidates create a narrative to address whether their action plan goal was met at the end of the two semester project.

E. UMUC faculty and staff continuously identify and make necessary modifications to programming within the MAT program at UMUC based upon the cross disciplinary tiered mentoring initiatives results garnered through various formative assessment results.

F. All data is sent to and analyzed by an evaluator. Data records will be kept and maintained in the Department of Education.

G. A half day retreat will be held at the midpoint, in May 2011, of the program and at the conclusion of the second semester between the mentors, mentees, mentor assistant, UMUC faculty and staff, onsite at a UMUC facility. A satisfaction survey will be provided at both meetings.

\section{E. Data Collection}

Immediately prior to the study, a demographic identification profile of the accepted teacher candidates, the mentees, was created. The demographics included occupation, background, start date in program, start date of mentor program, courses taken in their MAT program; gender, ethnicity, and content area that the teacher candidates hoped to eventually teach (See Table 1). Once the mentees were identified, a comparison group was created based upon the demographics of the individual students who were not accepted or did not apply to the mentor program. Data are currently being collected on the variables associated with student achievement, teacher candidate retention as compared with the comparison group, mentor and mentee satisfaction, and use of the technology videos for secondary students by the mentors in their own classrooms. Data are being collected primarily by the use of surveys, informative dialogue between mentor assistant and participants, and quantitative documentation of a variety of variables in prepared charts.

\section{PRE-LIMINARY RESULTS \& DISCUSSION}

Based upon the initial qualitative data that has been collected thus far, the majority of teacher candidates, the mentees, are happy to have a mentor and are gaining useful knowledge and learning about the role of collegiality in education from the experience. Upon viewing the current grades of teacher candidate mentees in their courses, the average GPA has held consistent to the GPA that the teacher candidates entered the program with. One limitation of this study may be that the students who have vol- untarily sought out a mentor are students who do well in their courses and may have continued in the program without a mentor. The next group of mentee teacher candidates may need to be identified as those with a lower GPA and encouraged to have a mentor. Comparison of data of mentees with lower initial GPA's to non-mentee teacher candidates with lower GPA's may shed more information on whether the mentor is a variable that assists in the retention of teacher candidates. We have had very little qualitative or quantitative data from the master mentor teachers. We have had one master mentor teacher who has stopped contacting her mentee and we are thus far unable to determine the reason. All other mentors are mentoring the teacher candidates. In order to discuss the other goals of the program, more data needs to be collected and analyzed. Data continues to be collected and results will be presented as the information is analyzed.

The project will be sustained by having MAT and Master in Instructional Technology (MEd.) graduates become the master mentor teachers, once they have been teaching in their own classrooms for a three year period, who will use technology and integrated STEM methods to increase academic achievement with their students. UMUC will continue to create a partnership with county schools and apply the knowledge gained to programming for future students in the MAT program to ensure that cross content integration related to STEM fields is embedded. The preliminary results will be shared with the session attendees with hopes of providing a viable model that can be replicated by other education and business constituents.

TABLE I

PERCENTAGE OF TEACHER CANDIDATE MENTEES BY DEMOGRAPHICS

\begin{tabular}{|c|c|c|c|}
\hline \multirow{2}{*}{$\begin{array}{c}\text { Mentees } \\
\text { by Con- } \\
\text { tent Area }\end{array}$} & \multicolumn{3}{|c|}{ All Mentee's Began January 2011 } \\
\cline { 2 - 4 } & $\%$ employed & Gender Ethnicity & Avg. GPA \\
\hline \multirow{3}{*}{1} & \multirow{2}{*}{$75 \%$} & $\begin{array}{r}50 \% \mathrm{M} \\
75 \% \mathrm{C} \\
50 \% \mathrm{~F}\end{array}$ & \multirow{2}{*}{4.0} \\
& & $25 \% \mathrm{AA}$ & \\
\hline \multirow{2}{*}{2} & \multirow{2}{*}{$50 \%$} & $100 \% \mathrm{~F}$ & \multirow{2}{*}{4.0} \\
\hline \multirow{3}{*}{3} & & $100 \% \mathrm{C}$ & \\
& $50 \%$ & $50 \% \mathrm{M}$ & \multirow{2}{*}{3.0} \\
& & $50 \% \mathrm{~F}$ & \\
\hline
\end{tabular}

1: Science, Technology, Engineering, or Math

2: English

3: Social Studies

C: Caucasian

U: Unspecified

AA: African American

M: Male

F: Female

\section{ACKNOWLEDGMENT}

I would like to thank Dr. Rana Kahn for her willingness to share her knowledge of online mentoring and the sharing of resources with her fellow colleagues.

\section{REFERENCES}

[1] DuFour, R. (2005). What is a professional learning community? In R. DuFour, R. Eaker, \& R. DuFour (Eds.), On common ground: The power of professional learning communities (pp. 31-43). Bloomington, IN. National Education Service. 
[2] Haslam, M.B. (2010). Teacher professional development evaluation guidelines. Prepared for the National Staff Development Council, Washington, DC

[3] Pohan, C.A., Ward, M., Kouzekanani, K., Boatright, C. (2009). The impact of field placements on preservice teachers' beliefs about teaching diverse students. School-University Partnerships, 3(1), 43-53.

[4] . Riel, M. \& Harasim, L.M. (1994). Research perspectives on network learning. Machine-Mediated Learning, 4, 91-113.

\section{AUTHOR}

Barbara Schwartz-Bechet is with University of Maryland University College, Adelphi, MD 20783 USA (email: bschwartz-bechet@umuc.edu.).

This work was supported in part by the University System of Maryland Redesign of Teacher Education Grant. This article is an extended version of a presentation at ICELW 2011 - The International Conference on E-learning in the Workplace, held from June 8th-10th, 2011 at Columbia University, New York, NY, USA. Received 31 March 2011. Published as resubmitted by the author August 82011. 